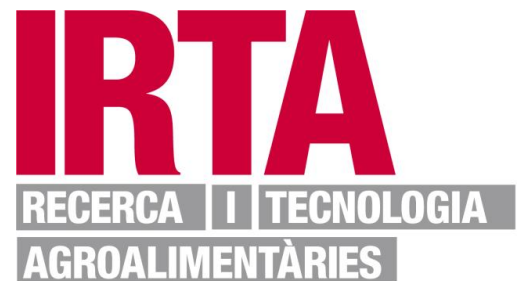

This is a post-peer-review, pre-copyedit version of an article published in Irrigation Science. The final authenticated version is available online at: https://doi.org/10.1007/s00271-018-0610-z

Document downloaded from:

RTA Pubpro

Open digital archive 


\section{INFLUENCE OF Wind DiRECTION ON THE SURFACE ROUGHNESS OF VineYARDS}

Joseph G. Alfieri ${ }^{1}$, William P. Kustas ${ }^{1}$, Hector Nieto ${ }^{2}$, John H. Prueger ${ }^{3}$, Lawrence E. Hipps ${ }^{4}$, Lynn G. McKee ${ }^{1}$, Feng Gao ${ }^{1}$, Sebastian $\operatorname{Los}^{4}$

${ }^{1}$ USDA ARS, Hydrology and Remote Sensing Laboratory, Beltsville, MD 20705-2350 USA

${ }^{2}$ Institute for Food and Agricultural Research \& Technology, Parc de Gardeny, Edifici Fruitcentre, 25003 Lleida, Spain

${ }^{3}$ USDA ARS, National Laboratory for Agriculture and the Environment, Ames, IA 50011 USA

${ }^{4}$ Plants, Soils and Climate Department, Utah State University, Logan, UT 84322-4820 USA

Corresponding author: Joseph G. Alfieri; joe.alfieri@ars.usda.gov

\section{Abstract}

2 Remote sensing-based models are the most viable means of collecting the high-resolution

3 spatially distributed estimates of evaporative water loss needed to manage irrigation and ensure

4 the effective use of limited water resources. However, due to the unique canopy structure and

5 configuration of vineyards, these models may not be able to adequately describe the physical

6 processes driving evapotranspiration from vineyards. Using data collected from 2014 to 2016 as

7 a part of the Grape Remote sensing Atmospheric Profile and Evapotranspiration Experiment

8 (GRAPEX), the twofold objective of this study was to $i$. identify the relationship between the

9 roughness parameters, zero-plane displacement height $\left(d_{o}\right)$ and roughness length for momentum

$10\left(z_{o}\right)$, and local environmental conditions, specifically wind direction and vegetation density and

11 ii. determine the effect of using these relationships on the ability of the remote sensing-based

12 Two-Source Energy Balance (TSEB) model to estimate the sensible $(H)$ and latent $(\lambda E)$ heat

13 fluxes. Although little variation in $d_{o}$ was identified during the growing season, a well-defined

14 sigmoidal relationship was observed between $z_{o}$ and wind direction. When the output from a

15 version of the TSEB model incorporating these relationships (TSEBVIN) was compared to output

16 from the standard model (TSEBSTD), there were large changes to the roughness parameters,

17 particularly $z_{o}$, but only modest changes in the turbulent fluxes. When the output from TSEBVIN 
18 was compared to that of a version using a parameterization scheme representing open canopies

19 (TSEBopN), the mean absolute difference between the estimates of $d_{o}$ and $z_{o}$ were $0.44 \mathrm{~m}$ and

$200.25 \mathrm{~m}$, respectively. While these values represent differences in excess of $45 \%$, the turbulent

21 fluxes differed by just $13 \mathrm{~W} \mathrm{~m}^{-2}$ or $10 \%$, on average. The results suggest that the TSEB model is

22 largely insensitive to changes in the roughness parameters. This also suggests that the

23 requirement for highly accurate roughness values has limited utility in the application of the

24 TSEB model in vineyard systems. Since there is no significant advantage to using the more

25 complex TSEBopn and TSEBvin models, it is recommended that the standard model be used. 


\section{INTRODUCTION}

In terms of both quantity and value, California is among the largest wine producing regions in the world. According to statistics compiled by the US Department of the Treasury (2017), California's average wine production during the last decade approaches $2.41 \mathrm{GL}$ (638 million gallons) of wine annually; this is nearly $90 \%$ of all US production. As a result, the

31 California wine industry contributes nearly $\$ 60 \mathrm{~B}$ to the state's economy and $\$ 115 \mathrm{~B}$ to the US

32 economy each year according to industry analyses (MKF Research, 2007; John Dunham and

33 Associates, 2016). In turn, the wine industry is dependent on the state's wine grape growers.

34 There are approximately 250,000 ha of wine grape vineyards in California producing $363 \mathrm{Gg}$ of

35 fruit valued at more than \$3B each year (California Department of Food and Agriculture, 2017).

Since California, like many other wine-producing regions, is characterized by limited rainfall and high evaporative demand during the growing season, irrigation is critical to ensure vineyard productivity. However, the timing and amount of water available can significantly impact the vine vigor, crop yield, and fruit quality (Chapman et al. 2005; Chaves et al. 2007;

Webb et al. 2007). For example, while adequate moisture is needed early in the growing season

41 from bud burst to fruit set to ensure crop yield, moderate water stress is preferred later in the

42 growing season to enhance fruit quality (Lobell et al. 2007; Zarrouk et al. 2012). Therefore,

43 careful irrigation management is of paramount importance to wine grape production (Ojeda et al.

44 2002; Pellegrino et al. 2005; Acevedo-Opazo et al. 2010; Bellvert et al. 2015). Moreover, the

45 factors influencing water availability, water loss via evapotranspiration, and crop water stress are

46 numerous and vary both spatially and temporally. Thus, as discussed by Arno et al. (2009),

47 Campos et al. (2010), and Pagay (2016), among others, precision methods for scheduling

48 irrigation at a sub-vineyard scale are needed so that both the timing and amount of water applied

49 to the vines is appropriate to their individual needs. 
Remote sensing-based approaches are the most viable means to monitor the within-field

51 variability in water loss and vine water stress needed for irrigation management decisions

52 (Baluja et al. 2012; Semmens et al. 2016; Xia et al. 2016). However, remote sensing-based

53 models also have limitations. One of these limitations is the simple empirical relations that are

54 typically used to determine the parameters that describe the aerodynamic roughness of the

55 surface which are used not only to calculate the wind profiles but also the resistance terms

56 needed to calculate the fluxes of heat and moisture. For instance, the thermal remote sensing-

57 based two-source energy balance model (TSEB; Norman et al.1995; Kustas and Norman1997,

58 1999, 2000), and the closely related ALEXI/DisALEXI modeling system (Anderson et al., 1997,

$592004,2007)$, determine two key roughness parameters, namely the zero-plane displacement

60 height ( $d_{o}$; referred to as displacement height hereafter) and roughness length for momentum ( $z_{o}$;

61 referred to as roughness length hereafter) as a fraction of vegetation height following the well-

62 known relationships given by Norman and Campbell (1980).

63 The surface roughness parameters, $d_{o}$ and $z_{o}$, describe the effect exerted by the surface on

64 near-surface wind flow due to drag. They are often defined in terms of Monin-Obukhov

65 Similarity Theory and the vertical profile of horizontal wind speed (Brutsaert 1982; Arya 2001).

66 In this framework, $\mathrm{z} o$ is defined as the height above the lower boundary of the logarithmic profile

67 where the horizontal wind speed goes to zero. Depending on the size and density of the

68 roughness elements, the position of the lower boundary lies somewhere between the base and top

69 of the roughness elements. As the name implies, the $d_{o}$ accounts for the height of the lower

70 boundary of the profile above the land surface. However, these quantities can also be defined in

71 terms of momentum transfer. In this context, $z_{o}$ characterizes the efficiency of momentum 
72 transport to the surface (Shaw and Pereira 1982) while $d_{o}$ indicates the mean height of

73 momentum transfer to the surface (Raupach 1992, 1994; Brunett et al. 1994)

74 The commonly-used relationships between $d_{o}, z_{o}$ and vegetation height, such as those

75 used by TSEB and ALEXI/DisALEXI, neglect numerous other factors including the spacing,

76 geometry, and frontal area that impact surface roughness by assuming dense closed canopy. (See

77 Brutsaert (1982) for a concise discussion of the evolution of these empirical relationships.) In

78 contrast, $d_{o}$ and $z_{o}$ for sparse or open canopies are also influenced by the organizational structure

79 of the canopy, i.e. the density and distribution of biomass (Shaw and Pereira 1982; Raupach

80 1992, 1994; Verhoef et al. 1997). As discussed by Zeng and Wang (2007), failing to account for

81 the factors beyond canopy height that can affect surface roughness, significant errors of up to

$8250 \%$ can be introduced into the estimates of $d_{o}$ and $z_{o}$. Other studies, such as Pitman (1994) and

83 Maurer et al. $(2013,2015)$ have shown errors in $d_{o}$ and $z_{o}$ can result in significant errors in

84 modeled fluxes of momentum, heat, and moisture.

85 Although the exact configuration varies from vineyard-to-vineyard, vineyards are

86 generally characterized by trellised vines that are between $1 \mathrm{~m}$ and $2.5 \mathrm{~m}$ in height and separated

87 by a broad inter-row space on the order of $3 \mathrm{~m}$ wide. Due to this design, it is likely that $d_{o}$ and $z_{o}$

88 are influenced other factors beyond vine height. Although studies are limited, past research also

89 suggests $d_{o}$ and $z_{o}$ are impacted by wind direction and vegetation density. The observational

90 studies of Hicks (1973) and Riou et al. (1987) suggests surface roughness varies with wind

91 direction while the work of Sene (1994) suggests that the surface roughness increases with

92 increasing vine density. These results are further supported by the work of Weiss and Allen

93 (1976), who found that turbulent intensity was greater when the wind flow was perpendicular to

94 the vine rows as opposed to parallel to them, and Padro et al. (1994), who found that the 
95 aerodynamic resistance over a vineyard changed as a function of wind direction. Most recently,

96 the large eddy simulation (LES) studies of Chahine et al. (2014) indicates that both $d_{o}$ and $z_{o}$ vary

97 with wind direction with the lowest $z_{o}$ and largest $d_{o}$ occurring when winds are parallel to the

98 rows.

99 Building on these earlier studies, the objective of this study was twofold. The first aim

100 was to identify a functional relationship between each of the roughness parameters, $d_{o}$ and $z_{o}$,

101 and both wind direction and vegetation density as expressed in terms of leaf area index (LAI).

102 The second objective was to evaluate the impact of allowing the roughness parameters to vary

103 dynamically in response to changing environmental conditions on the surface fluxes computed

104 by the TSEB model. The following section provides a description of field site, datasets, remote

105 sensing-based ET model, and analysis techniques. The third section discusses the results of this

106 study. Finally, the last section includes the conclusions and recommendations that can be drawn

107 from this work.

108 Materials AND Methods

109 Site Description

110 As can be seen in Figure 1, the study was conducted as a part of the Grape Remote

111 sensing Atmospheric Profile and Evapotranspiration eXperiment (GRAPEX) over a pair of

112 adjacent vineyards located near the city of Lodi in California's Central Valley, USA (38.29 N

$113121.12 \mathrm{~W}$ ). This region is characterized by warm, dry conditions and an evaporative demand

114 ranging from 889 to $1270 \mathrm{~mm}$ of water during the growing season, which is defined here as April

115 through August (Semmens et al. 2015). Also, the air temperature averages near $22^{\circ} \mathrm{C}$ and the

116 total precipitation is typically $24 \mathrm{~mm}$ during the same period. 

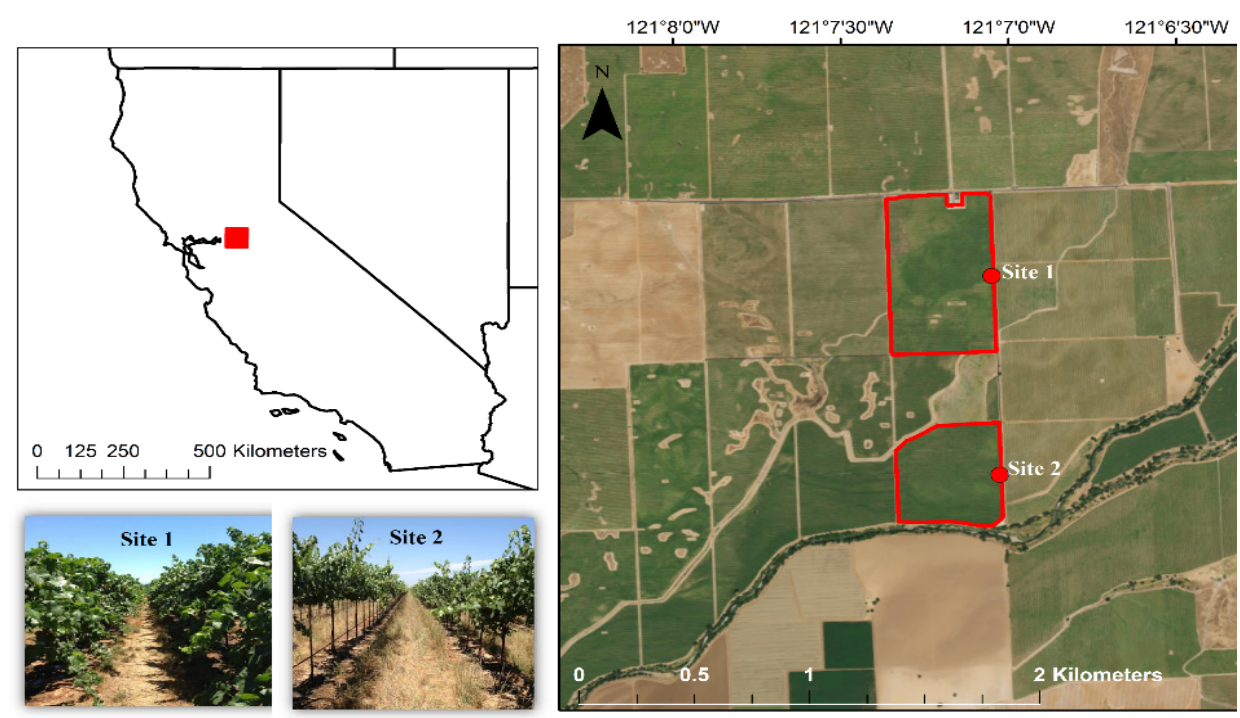

Figure 1 The location of study area is shown. The northern (Site 1) and southern (Site 2) vineyards are outlined in red while the location of the micrometeorological towers are represented by the red dots. The photo of the two vineyards were taken on August $6^{\text {th }}, 2013$.

Both vineyards are planted with Pinot Noir vines and share similar trellis structure and

118 vine management. The main shoots of the vines, which are planted every $1.52 \mathrm{~m}$ along the east-

119 west running trellising system, are attached to the quadrilateral cordon trellis at a height of 1.45

$120 \mathrm{~m}$. Although the height of the vines ranges between 2.0 and $2.5 \mathrm{~m}$, the plant biomass is

121 concentrated in the upper third of the canopy. The rows are oriented east-west with an inter-row

122 spacing between the trellises is $3.35 \mathrm{~m}$. This inter-row space is planted with a grass cover crop to

123 regulate soil moisture early in the growing season following the winter season when this region

124 receives virtually all of it rainfall. The cover crop enters senescence in mid-March and is mowed

125 in late April or early May. As a result, the cover crop is inactive during the period considered in

126 this study.

Other management practices shared by the two vineyards include the timing and amount of drip irrigation, pruning activities, and application of agrochemicals. 
130 the northern vineyard (Site 1) were more mature having been planted in 2005 while the southern

131 vineyard (Site 2) was planted in 2009. The northern vineyard, which has an area of 35 ha, is also

132 somewhat larger than the southern vineyard; the latter has an area of 21 ha.

Data Collection and Post-Processing conditions used in this study were collected using identical instrument packages. The wind velocity profiles were collected using four sonic anemometers (CSAT3 ${ }^{1}$, Campbell Scientific,

137 Logan, Utah) mounted facing due west $\left(270^{\circ}\right)$ at $2.5 \mathrm{~m}, 3.75 \mathrm{~m}, 5 \mathrm{~m}$ and $8.0 \mathrm{~m}$ agl, respectively.

138 The turbulent energy fluxes were determined via the eddy covariance method using a sonic anemometer (CSAT3, Campbell Scientific, Logan, Utah) to measure the orthogonal wind

140 velocity components and an infrared gas analyzer (EC-150, Campbell Scientific) to measure the

141 water vapor and carbon dioxide concentrations. Both sensors were mounted at $5 \mathrm{~m}$ agl facing due

142 west and operated using a sampling frequency of $20 \mathrm{~Hz}$. The net radiation was determined from

143 measurements collected via a four-component radiometer (CNR-1, Kipp and Zonen, Delft,

144 Netherlands) mounted $6 \mathrm{~m}$ agl. The soil heat flux was calculated as the average of 5 heat flux

145 plates (HFT-3, Radiation Energy Balance Systems, Bellevue, Washington) deployed at a depth 8

$146 \mathrm{~cm}$ along a diagonal transect across the inter-row space. A pair of thermocouples, which were

147 buried at depths of $2 \mathrm{~cm}$ and $6 \mathrm{~cm}$, and a soil moisture sensor (HydraProbe, Stevens Water

148 Monitoring System, Portland, Oregon), which was buried at a depth of $5 \mathrm{~cm}$, was co-located with

149 each heat flux plate. Additional auxiliary measurements were collected using a combined

\footnotetext{
1 The use of trade, firm, or corporation names in this article is for the information and convenience of the reader. Such use does not constitute official endorsement or approval by the US Department of Agriculture or the Agricultural Research Service of any product or service to the exclusion of others that may be suitable
} 
150 humidity and temperature sensor (HMP45C, Vaisala, Helsinki, Finland) mounted $5 \mathrm{~m}$ agl, two

151 thermal infrared thermometers (SI-111, Campbell Scientific) mounted $2.5 \mathrm{~m}$ agl at a $45^{\circ}$ to the

152 surface, and a tipping bucket rain gauge (TE525, Texas Electronics, Dallas, Texas),

153 The high-frequency $(20 \mathrm{~Hz})$ wind velocity data collected as a part of the wind profiles

154 were post-processed by first screening the raw data to identify and remove without replacement

155 nonphysical values and data spikes following the method of Goring and Nikora (2002). Then, the

156 coordinate system of the wind velocity components was rotated to align with prevailing wind

157 direction (Tanner and Thurtell, 1969; Kaimal and Finnigan, 1994). Finally, the hourly mean

158 wind speed and direction was calculated.

159 Similarly, the flux data were post-processed using the full suite of standard corrections

160 and adjustments. Nonphysical values and data spikes were removed without replacement from

161 the high frequency data and a two-dimensional coordinate rotation was applied to the wind

162 velocity data following the same procedures as used with the wind profiles. Also, the sonic

163 temperature was converted to air temperature by adjusting for humidity effects following the

164 approach described by Liu et al. (2001). Third, the data were corrected for sensor displacement

165 and frequency response attenuation according to the methods outlined by Massman (2000) and

166 Massman and Lee (2002). Finally, hourly turbulent fluxes were calculated. The moisture and

167 carbon dioxide fluxes were then corrected for the effects of buoyancy and water vapor density

168 (Webb et al., 1980).

169 Leaf Area Index

170 The leaf area index was estimated from satellite imagery for each year during the

171 GRAPEX project using the reference-based technique of Gao et al. (2012). The technique uses

172 the relationship between the LAI of homogenous MODIS pixels (500 $\mathrm{m}$ resolution) and the 
173 surface reflectance of the corresponding Landsat pixels to develop a regression tree. The

174 resulting regression tree was then applied to the Landsat imagery to generate a LAI map at 30-m

175 spatial resolution. The LAI map was smoothed and gap-filled to generate daily LAI using the

176 Savitzky-Golay filter approach (Jonsson and Eklundh 2004). Since the experimental sites locate

177 in the overlapped area of two adjacent Landsat paths, over 60 clear Landsat 7 and 8 images were

178 acquired each year from 2013 to 2016 . The resulting LAI curves agreed with in-situ observation

179 to within $5 \%$ to $10 \%$, on average. Details of the procedure and resulting LAI product used in this

180 study are provided in Sun et al (2017).

181 Two-Source Energy Balance Model Description

182 The two-source energy balance model (TSEB), which was originally developed by

183 Norman et al. (1995) and Kustas and Norman (1997, 1999, 2000), uses radiometric surface

184 temperature $\left(T_{r}\right)$ to determine the surface energy fluxes while explicitly considering the separate

185 contributions of the soil and canopy. More specifically, the model uses $T_{r}$, meteorological data

186 such as wind speed $(U)$, and vegetation characteristics such as leaf area index (LAI) to

187 simultaneously solve a family of equations describing the energy fluxes from the soil and

188 canopy. Although a detailed description of the model can found elsewhere, e.g. Kustas and

189 Norman (2000) and Kustas et al. (2012), a brief overview is provided here.

To begin, TSEB defines the $T_{r}$ as the area-weighted average of the temperatures of the

191 canopy and soil surface:

$192 T_{r}(\phi)=\left\{f_{c}(\phi) T_{c}^{4}+\left[1-f_{c}(\phi)\right] T_{s}^{4}\right\}^{1 / 4}$

193 where $T_{r}(\phi)$ is the radiometric surface temperature as a function of view angle $\phi, f_{c}(\phi)$ is the

194 fractional vegetation cover as a function of $\phi, T_{c}$ is the canopy temperature, and $T_{s}$ is the soil

195 surface temperature. The fractional vegetation cover is derived from LAI according to: 
$196 f_{c}(\phi)=1-\operatorname{EXP}\left(-\frac{\Omega \mathrm{LAI}}{2 \operatorname{Cos} \phi}\right)$

197 where $\Omega$ is a dimensionless clumping index, which indicates the degree heterogeneity in the

198 spatial distribution of the leaf area (Anderson et al., 2005) and the other terms are defined above.

199 Additionally, TSEB defines the energy budgets of the soil surface and canopy,

200 respectively, as follows:

$201 \quad R_{N s}=H_{s}+\lambda E_{s}+G$

$202 R_{N c}=H_{c}+\lambda E_{c}$

203 where $R_{N}$ is the net radiation, $H$ is the sensible heat flux, and $\lambda E$ is the latent heat flux. The

204 subscript $s$ refers to the soil surface while the subscript $c$ refers the canopy.

205 The net radiation for the soil and canopy are determined using a simplified radiation

206 transfer model (Kustas and Norman 2000) while $G$ is computed following a modification of the

207 method described by Santanello and Friedl (2003). Rather than using the sinusoidal function

208 given by Santanello and Friedl (2003) to describe the relationship between $G$ and $R_{n}$ over time, a

209 double asymmetric sigmoid function was used because it better fit the observed relationship at

210 the study site (Nieto et al., this issue, a). That work showed the ratio of $G$ to $R_{n}$ varied from a

211 minimum of -0.5 near sunrise/sunset to maximum near 0.35 at mid-day.

212 For the soil surface and canopy, respectively, $H$ is calculated according to:

$213 H_{s}=\rho C_{p} \frac{T_{s}-T_{a c}}{r_{s}}$

$214 H_{c}=\rho C_{p} \frac{T_{c}-T_{a c}}{r_{x}}$

215 where $\rho$ is the air density, $C_{p}$ is the specific heat of air, $T_{a c}$ is the within-canopy air temperature,

$216 r_{s}$ is the resistance of the soil surface to heat exchange, $r_{x}$ is the resistance of the total canopy to 
217 heat exchange, and the other terms are defined above. In turn, $\lambda E_{s}$ is calculated as a residual

218 while $\lambda E_{c}$ is calculated according to:

$219 \lambda E_{c}=\alpha f_{c} \frac{\Delta}{\Delta+\gamma} R_{N c}$

220 where $\alpha$ is the Priestley-Taylor coefficient (Priestley and Taylor 1972) which has an initial value

221 of $1.26, \Delta$ is the slope of the saturation vapor pressure-temperature curve, $\gamma$ is the psychrometric

222 constant, and the other terms are defined above.

223 The resistance of the soil surface to heat exchange $\left(r_{s}\right)$ was estimated based on a modified

224 form of the empirical approach of Sauer et al. (1995) developed by Kustas and Norman (2000):

$225 r_{s}=\left[a\left(T_{s}-T_{a c}\right)^{1 / 3}+b U_{s}\right]^{-1}$

226 where both $a\left(0.0025 \mathrm{~m} \mathrm{~K}^{-1} \mathrm{~s}^{-1}\right)$ and $b(0.012)$ are constants, $U_{s}$ is the wind speed just above the

227 soil surface where the effects of soil roughness is minimal, and the other terms are defined

228 above. In turn, $U_{s}$ is calculated according to Goudriann (1977):

$229 U_{s}=U_{c} E X P\left[-0.28 \sqrt[3]{\frac{\mathrm{LAI}^{2} h_{c}}{\ell}}\left(1-\frac{1}{20 h_{c}}\right)\right]$

230 where $U_{c}$ is the wind speed at the top of the canopy, $h_{c}$ is the canopy height, $\ell$ is the mean leaf

231 size, and the other terms are defined above. Similarly, $U_{c}$ calculated according to Goudriann

232 (1977) as follows:

$233 \quad U_{c}=U\left[\frac{\ln \left(\frac{h_{c}-d_{o}}{z_{o}}\right)}{\ln \left(\frac{z-d_{o}}{z_{o}}\right)-\Psi}\right]$

234 where $U$ is the wind speed at height $z$ above the canopy, $d_{o}$ is the displacement height, $z_{o}$ is the

235 roughness length for momentum, $\Psi$ is the correction for atmospheric stability, and the other

236 terms are defined above. Finally, as described by Norman et al. (1995), $r_{x}$ is defined as:

$237 \quad r_{x}=\frac{c \sqrt{\ell / U_{d}}}{\mathrm{LAI}}$ 
238 where $c\left(90 \mathrm{~s}^{1 / 2} \mathrm{~m}^{-1}\right)$ is a constant and $U_{d}$ is determined analogously to $U_{s}$ as:

$239 U_{d}=U_{c} E X P\left[-0.28 \sqrt[3]{\frac{\mathrm{LAI}^{2} h_{c}}{\ell}}\left(1-\frac{z_{o}+d_{o}}{h_{c}}\right)\right]$

240 and the other terms are defined above.

241 For the standard version of the TSEB model (TSEBSTD), the roughness parameters, $d_{o}$

242 and $z_{o}$ are estimated using the well-known empirical functions of $h_{c}$ given by Norman and

243 Campbell (1980), among others:

$244 d_{o}=\frac{2}{3} h_{c}$

$245 \quad z_{o}=\frac{h_{c}}{8}$

246 For this study, $h_{c}$ of the vineyard that was used by the TSEB model was estimated as a function

247 of LAI (see Nieto et al., this issue, b). Using a typical vines height of $2.25 \mathrm{~m}$ for the GRAPEX

248 field sites, these relationships estimate $d_{o}$ and $z_{o}$ as $1.50 \mathrm{~m}$ and $0.28 \mathrm{~m}$, respectively.

249 Numerous studies, such as Shaw and Pereira (1982), has demonstrated that the roughness

250 length is influenced by other factors beyond $h_{c}$; this is particularly true of sparse open canopies.

251 Thus, due to the configurations of vineyards, the standard approach for estimating the roughness

252 parameters may not be the most appropriate. Therefore, an alternate version of the TSEB model

253 (TSEBOPN) was also used in this study. This version of the model uses the approach of Schaudt

254 and Dickinson (2000) to estimate the roughness parameters. The approach builds on the earlier

255 work of Raupach (1992) and Lindroth (1993) to consider canopy shape and density, in addition

256 to $h_{c}$, when estimating $d_{o}$ and $z_{o}$.

257 The method of Schaudt and Dickinson (2000) begins with the assumption that the

258 vegetation height of woody vegetation changes little over time. Instead, the roughness changes in

259 response to changes in vegetation density, i.e. LAI, and the frontal area of the vegetation. The 
260 frontal area is the projected area of the canopy perpendicular to the wind direction of that

261 intercept and interacts with the air flow; it is a function of the canopy height, width, and shape

262 (Raupach 1992, 1994). From this Raupach (1994) proposed the frontal leaf area index $\left(\lambda_{c}\right)$

263 defined as:

$264 \lambda_{c}=f_{c} \frac{h_{c}}{w_{c}}$

265 where $f_{c}$ is the fractional canopy cover, $w_{c}$ is the canopy width, and the other terms are defined as

266 above. He further proposed the following relations for $d_{o}$ and $z_{o}$ as a function of $\lambda_{c}$ :

$267 d_{o}=h_{c}\left[1-\frac{1-e^{-\left(a \lambda_{c}\right)^{1 / 2}}}{\left(a \lambda_{c}\right)^{1 / 2}}\right]$

$268 \quad z_{o}=\left\{\begin{array}{cc}h_{c}\left[b_{1} \lambda_{c}^{c_{1}} e^{-d \lambda_{c}^{e_{1}}}+f_{1}\right] & \lambda_{c} \leq 0.152 \\ h_{c}\left[b_{2} \lambda_{c}^{c_{2}}\left(1-e^{-d \lambda_{c}^{e_{2}}}\right)+f_{2}\right] & \lambda_{c}>0.152\end{array}\right.$

269 where $a(15.0), b_{1}(5.86), b_{2}$ (0.0537), $c_{1}(1.33), c_{2}(-0.51), d(10.9), e_{1}(1.12), e_{2}(0.874)$,

$270 f_{1}\left(8.6 \times 10^{-4}\right)$, and $f_{2}\left(3.68 \times 10^{-3}\right)$ are coefficients and the other terms are defined as above.

271 Finally, using the Schaudt and Dickinson (2000) approach, the roughness parameters used by the

272 model are calculated as the product of these initial estimates and a correction factor. The

273 correction factor for $d_{o}$ and $z_{o}$, respectively, are:

$274 f_{d}=1-a e^{-b \mathrm{LAI}}$

$275 f_{z}= \begin{cases}c_{1} \mathrm{LAI}^{3 / 2}+d_{1} & \mathrm{LAI} \leq 0.8875 \\ c_{2} e^{-d_{2} \mathrm{LAI}}+1 & \mathrm{LAI}>0.8875\end{cases}$

276 where $a(0.3991), b(-0.1779), c_{1}(0.3299), c_{2}\left(1.6771, d_{1}(2.1713)\right.$, and $d_{2}(0.1717)$ are

277 coefficients and the other terms are defined as above. 
Finally, a version of the TSEB model (TSEBVIN) that uses the relationships developed by

279 this study was also used herein to evaluate the impact of the roughness parameterization on the

280 modeled fluxes.

281 Calculation of Roughness Parameters

282 Using the data collected during the 2014 to 2016 growing seasons as a part of the

283 GRAPEX project, $d_{o}$ and $z_{o}$ were calculated assuming a logarithmic wind profile and neutral

284 atmospheric stability conditions. Under these conditions, the wind speed can be expressed as a

285 function of height:

$286 \quad U=\frac{u_{*}}{k} \ln \left(\frac{z-d_{o}}{z_{o}}\right)$

287 where $u *$ is the friction velocity, $k$ is the von karmann constant, and the other terms are defined

288 above (Stull, 1988; Arya, 2001). Based on this relation, the $d_{o}$ can be determined using paired

289 measurements of wind speed taken at two different heights as follows:

$290 \quad d_{o}=z_{1}-\frac{\Delta z}{e^{k \Delta U / u_{*}-1}}$

291 where $z_{1}$ is the lower measurement height, $\Delta z$ is the separation distance between the two

292 measurements, $\Delta U$ is the difference in the measured wind speed, and the other terms are defined

293 above. Once $d_{o}$ is determined, $z_{o}$ can be calculated by rearranging Eq. (15):

$294 \quad z_{o}=\frac{z-d_{o}}{e^{k U / u_{*}}}$

295 This approach, and particularly the determination of $d_{o}$, is highly sensitive to any errors in

296 the measurements and any violations of the underlying assumptions (Brutsaert, 1982). For

297 example, a preliminary sensitivity analysis for the GRAPEX study sites indicates a 5\% error in

$298 \Delta U$ results in a $5 \%$ to $15 \%$ error in the calculated $d_{o}$, depending on the measurement heights 
used. Therefore, the data used were restricted to clear-sky days with near-neutral stability and

300 sufficient turbulent mixing (See Table 1 for a complete listing of constraints).

For each vineyard and time period identified as valid, all possible measurement height

302 combinations - for the purpose of this study, the wind speed measurements from the eddy

303 covariance system were also included as a part of the profile - were used to estimate $d_{o}$ following

304 Eq. (16). As a further quality control step, the six estimates of $d_{o}$ were compared. If they agreed

305 to within $10 \%, d_{o}$ during the period was taken as the average of all of the $d_{o}$ estimates. If there

306 was disagreement among the estimates of $d_{o}$, the period was neglected in the subsequent analysis

307 of $d_{o}$. Due to the constraints placed on the calculation of $d_{o}$, there were only a small number of $d_{o}$

308 values obtained for each vineyard each year (see below for additional information). As a result,

309 the mean $d_{o}$ value $(1.40 \mathrm{~m})$ was used in the subsequent calculation of $z_{o}$.

310 The roughness length was calculated in a similar manner. For each vineyard, the valid

311 periods conforming to the constraints listed in Table1 were first identified. Then $z_{o}$ was estimated

312 for each measurement height in the profile using Eq. (17). Again, as a further quality control

313 step, the four estimates of $z_{o}$ for each period were compared and only if they agreed to within

$314 \quad 10 \%$ was the average used for subsequent analyses.

Table 1 The conditions used to constrain the data used to calculate the displacement height and roughness length are listed.

\begin{tabular}{|l|c|c|}
\hline \multicolumn{1}{|c|}{ Condition } & $\begin{array}{c}\text { Constraint for } \\
\text { Displacement Height }\end{array}$ & \multicolumn{1}{c|}{$\begin{array}{c}\text { Constraint for } \\
\text { Roughness Length }\end{array}$} \\
\hline Incident Solar Radiation $\left(K_{\downarrow}\right)$ & \multicolumn{2}{|c|}{$K_{\downarrow} \geq 100 \mathrm{~W} \mathrm{~m}^{-2}$} \\
\hline Wind Speed $(U)$ & \multicolumn{2}{|c|}{$U \geq 1 \mathrm{~m} \mathrm{~s}^{-1}$} \\
\hline Wind Direction $(\varphi)$ & $\left|\varphi-270^{\circ}\right| \leq 90^{\circ}$ \\
\hline Friction Velocity $(u *)$ & & \multicolumn{2}{|c|}{$u * 0.1 \mathrm{~m} \mathrm{~s}^{-1}$} \\
\hline Atmospheric Stability $(\zeta)$ & $-0.02 \leq \zeta \leq 0.01$ & \multicolumn{1}{c|}{$-0.04 \leq \zeta \leq 0.02$} \\
\hline
\end{tabular}


316 somewhat compared to those used for estimating $d_{o}$. Specifically, the range of near-neutral

317 conditions was extended slightly. Calculations of $d_{o}$ are substantially more sensitive to

318 departures from neutral conditions than the determination of $z_{o}$. By using a $u^{*}\left(0.31 \mathrm{~m} \mathrm{~s}^{-1}\right)$ typical

319 of the sites and the stability corrections given by Paulson (1970) and Dyer (1974), the percent

320 error of the estimates of the roughness parameters was calculated as a function of atmospheric

321 stability. To account for the effects of atmospheric stability, Eq. (16) and Eq. 17 were modified

322 to include the stability correction; respectively, for $d_{o}$ and $z$, the modified relationships are:

$323{ }^{c} d_{o}=z_{1}-\frac{\Delta z}{e^{k \Delta U / u_{*}+\Delta \psi_{-}}}$

$324 \quad{ }^{c} Z_{o}=\frac{z-d_{o}}{e^{k U / u_{*}+\psi}}$

325 where ${ }^{c} d_{o}$ and ${ }^{c} z_{o}$ are the estimates of $d_{o}$ and $z_{o}$ under non-neutral conditions, $\psi$ is the stability

326 correction, and the other terms are defined as above. The percent error is then defined as:

$327 \quad \epsilon_{p c t}=100 \frac{\left|n^{n} x-{ }^{c} x\right|}{c_{x}}$

328 where $\epsilon_{p c t}$ is the percent error, ${ }^{n} x$ is the estimate of the quantity of interest - either $d_{o}$ and $z_{o}-$

329 assuming neutral conditions, and ${ }^{c} x$ is the estimate of the quantity of interest calculated according

330 to Eq. (18). 


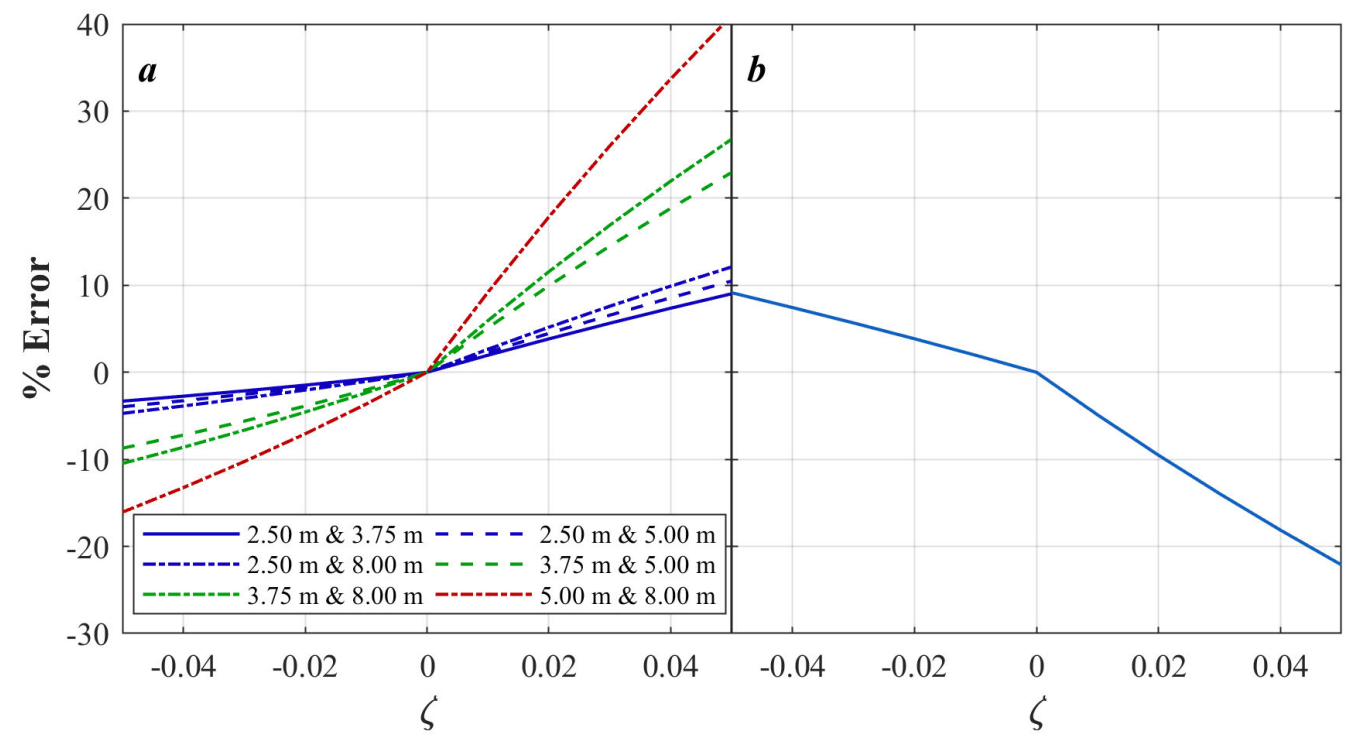

Figure 2 The percent error of the estimates of $\boldsymbol{a}$ ) displacement height and $\boldsymbol{b}$ ) roughness length as a function of atmospheric stability.

331 As can be seen in Figure 2, the percent error introduced into the estimates of $z_{o}$ by non-neutral

332 conditions is approximately half that introduced into the estimates of $d_{o}$. Thus, the range of $\zeta$

333 allowed when estimating $z_{o}$ can be extended to -0.04 and 0.02 while introducing less than $10 \%$

334 error. While the impact of atmospheric stability on the estimates of $d_{o}$ varies as a function of the

335 measurement heights used, this is the same maximum error as was allowed for the estimates of

$336 d_{0}$.

337 Statistical Analysis

338 A pair of well-established statistics were used to evaluate the model output of both the

339 standard and modified TSEB model. The first is the root mean square difference (RMSD) which

340 is defined as:

341

$$
\operatorname{RMSD}=\sqrt{\frac{1}{n} \sum_{i=1}^{n}\left(x_{i}-y_{i}\right)^{2}}
$$


342 where $x$ and $y$ are two estimates of some quantity of interest, $n$ is the number of paired data

343 points, and $i$ is an index. The RMSD can be separated into random and systemic and components

344 according to:

$345 \operatorname{RMSD}_{R}=\sqrt{\frac{1}{n} \sum_{i=1}^{n}\left(y_{i}-p_{i}\right)^{2}}$

$346 \operatorname{RMSD}_{S}=\sqrt{\frac{1}{n} \sum_{i=1}^{n}\left(p_{i}-x_{i}\right)^{2}}$

347 where $p$ is the value predicted by ordinary least-squares regression of $y$ against $x$ and the

348 remaining terms are defined above (Willmott 1982; Alfieri et al. 2011).

349 Since the squared difference terms in the RMSD tends to overemphasize the effects of

350 large differences (Legates and McCabe, 1999; Willmott and Matsuura, 2005; Willmott et al.,

351 2012), the mean absolute difference (MAD) was also used. This second metric is defined as:

$352 \quad \mathrm{MAD}=\frac{1}{n} \sum_{i=1}^{n}\left|x_{i}-y_{i}\right|$

353 where the terms are defined as above. Note that if $\mathrm{x}$ and $\mathrm{y}$ are the actual (observed) and modeled

354 flux, respectively, then RMSD and MAD, are indicative of the model error. The two metrics are

355 equivalent to the root mean square error (RMSE) and mean absolute error (MAE).

356 Results AND Discussion

357 Estimates of the Displacement Height

358 After using the criteria in Table 1 to parse the data collected during the growing seasons

359 from 2014 to 2016 over Vineyard 1, a total of 52 valid periods were identified. During the same

360 timeframe only 10 valid periods were identified at Vineyard 2. While the valid periods identified

361 over the two site differ in terms of wind speed, wind direction, and LAI, they all represent

362 periods when $H$ was near zero and the atmospheric stability was very close to neutral. The

363 difference in the number of near-neutral periods at the two sites is likely due to differences in 
364 vegetation density. During the growing season, the LAI of Vineyard 2 was approximately 0.25

$365 \mathrm{~m}^{2} \mathrm{~m}^{-2}$ or $10 \%$ to $25 \%$ less than the LAI at Vineyard 1. Because of the lower LAI, the amount of

366 transpiration is reduced while the surface temperature is increased at Vineyard 2. Both of these

367 effects act to increase $H$ and, thereby, unstable atmospheric conditions over Vineyard 2. A

368 comparison of the daytime $H$ and atmospheric stability ( $\zeta)$ collected at each vineyard during the

369 growing season further supports this hypothesis. Over the 4 years of GRAPEX, the daytime $H$ at

370 Vineyard 2 averaged $144 \mathrm{~W} \mathrm{~m}^{-2}$ or approximately $30 \mathrm{~W} \mathrm{~m}^{-2}$ greater than the mean at Vineyard 1.

371 Similarly, for the same timeframe, $\zeta$, which is the ratio of measurement height to Obukhov

372 length, was 0.09 lower at Vineyard 2 compared to Vineyard 1.

It. was not possible to determine the relationship between $d_{o}$ and site characteristics, such

374 as LAI, because only a limited range of environmental conditions are represented by the data due
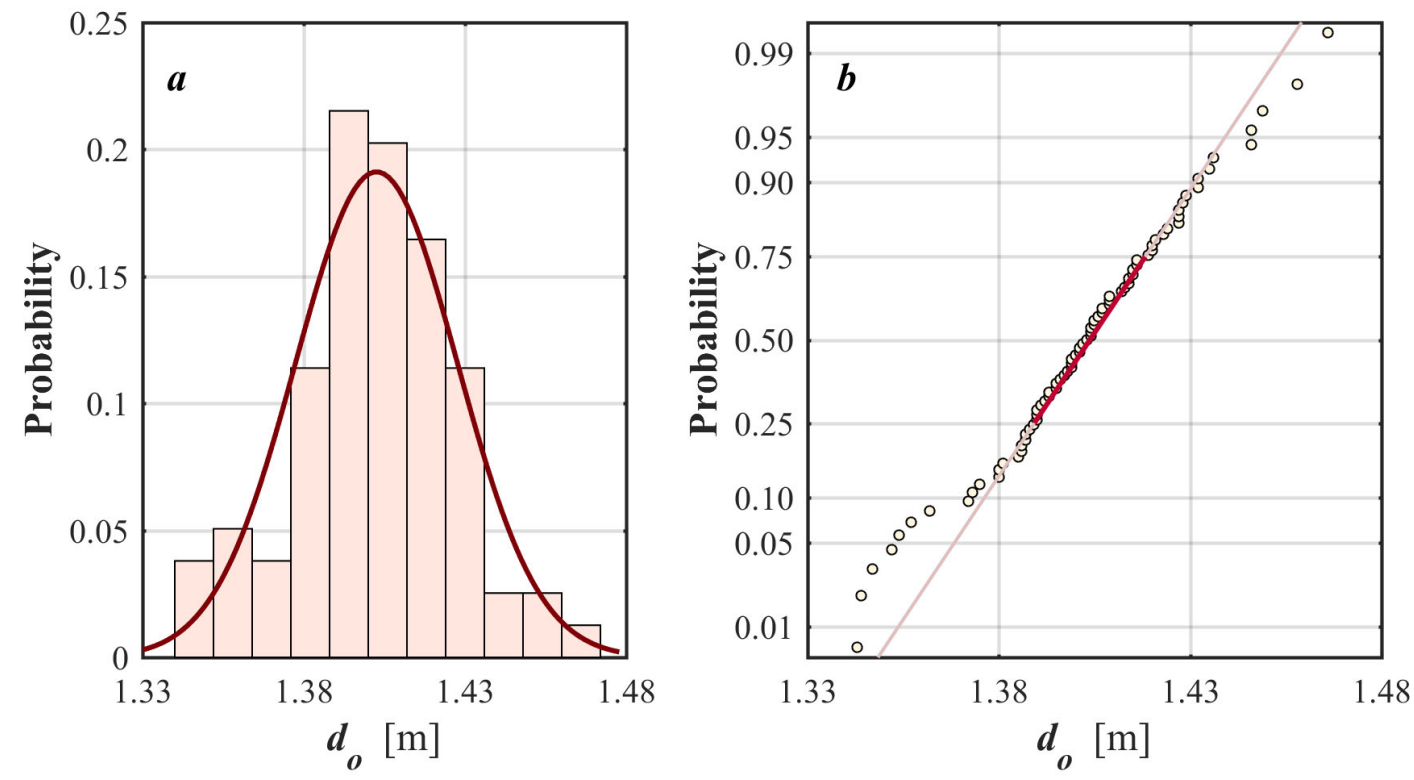

Figure 3 The $a$ ) histogram overlaid with corresponding probability density function and $\boldsymbol{b}$ ) probability plot for the pooled estimates of the displacement height show that the quantity is normally distributed. 
376 example of the clustering, half of the valid periods identified at Vineyard 1 during 2015 occurred

377 on either 9 or 10-June. However, by pooling the data over both sites and all years, it was found

378 that the estimates of $d_{o}$ calculated for the valid periods, which ranged between $1.34 \mathrm{~m}$ and 1.47

$379 \mathrm{~m}$, were normally distributed and averaged $1.40 \mathrm{~m}$ with a standard deviation of $0.03 \mathrm{~m}$ (Fig.3).

380 The mean $d_{o}$ estimate is very near the center of the vine biomass which is approximately $1.45 \mathrm{~m}$,

381 the height where the vines are attached to the trellis. This agrees with the definition of $d_{o}$ as the

382 mean height of momentum absorption by a rough surface (Raupach 1992, 1994). The mean value

383 of $d_{o}$ was used for both the calculation of $z_{\mathrm{o}}$ and the model simulations.

384 Estimates of the Roughness Length

385 After relaxing the constraints, between 36 and 40 valid periods were identified each year

386 at Vineyard 1 while between 8 and 28 valid periods were identified for Vineyard 2 (Table 2). To

387 investigate the relationship between $z_{o}$ and LAI, the data from each year at Vineyard 1 was bin-

388 averaged based on the corresponding LAI. The same was done for the data collected at Vineyard

3892 for 2014 and 2016, the 2 years when sufficient valid periods were identified at this site.

390 However, no relationship was evident. This is likely due to relatively small range of LAI

391 represented by the periods identified as valid. An example using the data collect at Vineyard 1

392 during 2015 is shown in Figure 4represented by the periods identified as valid. An example using

393 the data collect at Vineyard 1 during 2015 is shown in Figure 4. 
Table 2 Summary statistics for roughness length for each study site and year.

\begin{tabular}{|c|c|c|c|}
\hline \multirow{2}{*}{ Statistic } & \multicolumn{3}{|c|}{ Year } \\
\cline { 2 - 4 } & $\mathbf{2 0 1 4}$ & $\mathbf{2 0 1 5}$ & $\mathbf{2 0 1 6}$ \\
\hline $\mathbf{4}$ & 40 & 34 & 40 \\
\hline Mean & 0.244 & 0.242 & 0.237 \\
\hline $\begin{array}{l}\text { Standard } \\
\text { Deviation }\end{array}$ & 0.067 & 0.042 & 0.065 \\
\hline \multicolumn{4}{|c|}{ Vineyard 2} \\
\hline n & 26 & 8 & 28 \\
\hline Mean & 0.226 & 0.183 & 0.232 \\
\hline $\begin{array}{l}\text { Standard } \\
\text { Deviation }\end{array}$ & 0.049 & 0.041 & 0.056 \\
\hline
\end{tabular}

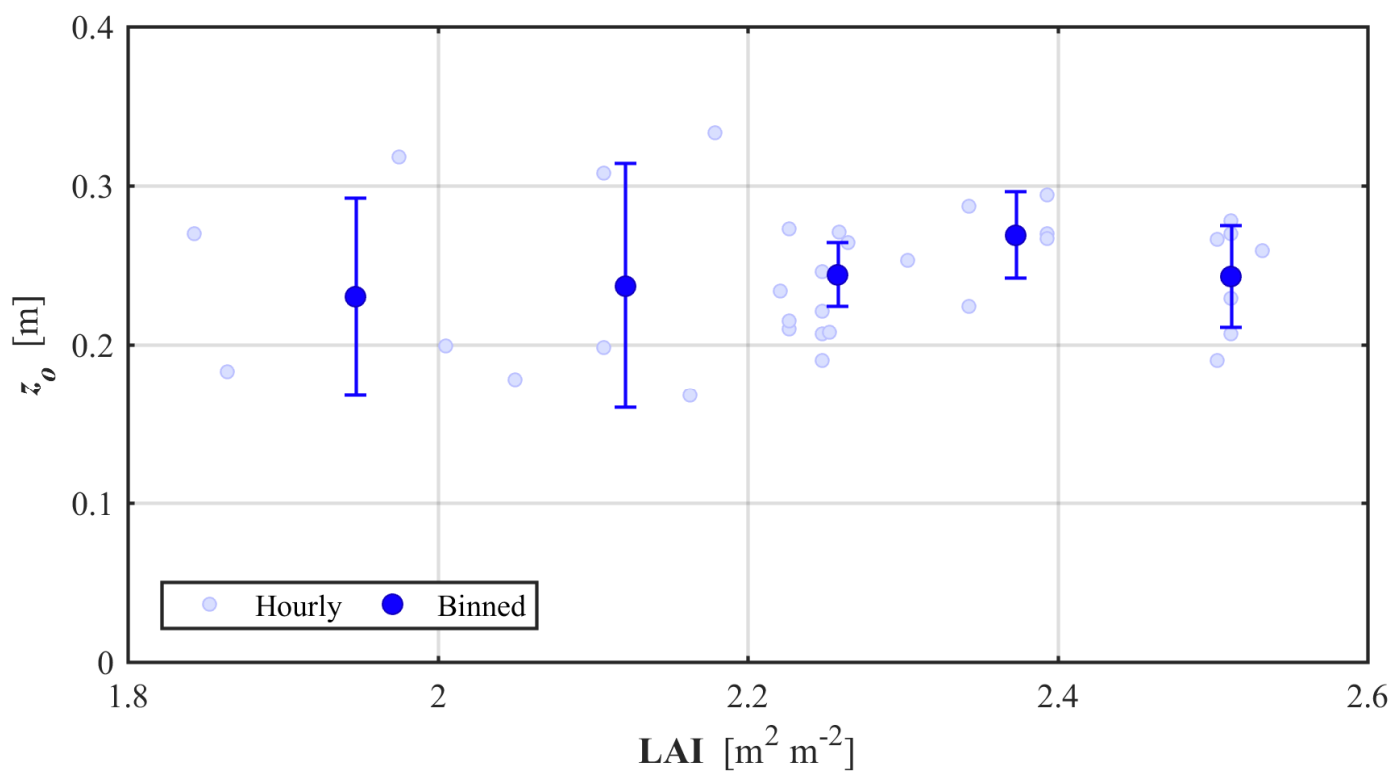

Figure $4 \mathrm{~A}$ plot of the roughness length $\left(z_{0}\right)$ as a function of leaf area index (LAI) using the data collected at Vineyard 1 during 2015 showing the lack of a relationship between the two quantities. The error bars indicate \pm 1 standard deviation. 
The same procedure was used to identify the potential linkage between $z_{o}$ and the wind

395 direction relative to the row orientation. The relative wind direction $(\omega)$ is defined as $0^{\circ}$ when the

396 wind direction was parallel to the row direction, i.e. east to west, and $90^{\circ}$ when the wind

397 direction was perpendicular to the row. In this case, clear sigmoidal relationships were identified

398 (Fig. 5) with the minimum $z_{o}$ occurring when the winds were parallel to the row. These

399 relationships can be expressed mathematically as:

400

$z_{o}=\xi_{\min }+\frac{\xi_{\max }-\xi_{\min }}{1+e^{-\beta\left(\omega-w_{o}\right)}}$

$401 \mathrm{w}$ here $\xi_{\min }, \xi_{\max }, \beta, \omega_{o}$ are fitting coefficients representing the minimum $z_{o}$, maximum $z_{o}$, slope,

402 and offset in $\omega$, respectively. Overall, with an average percent error of less than $1.5 \%$, these

403 relationships reproduced the observed $z_{o}$ quite well; the MAE ranges between $0.002 \mathrm{~m}$ and

$4040.008 \mathrm{~m}$ while the RMSD ranges between $0.002 \mathrm{~m}$ and $0.014 \mathrm{~m}$ (Table 3).

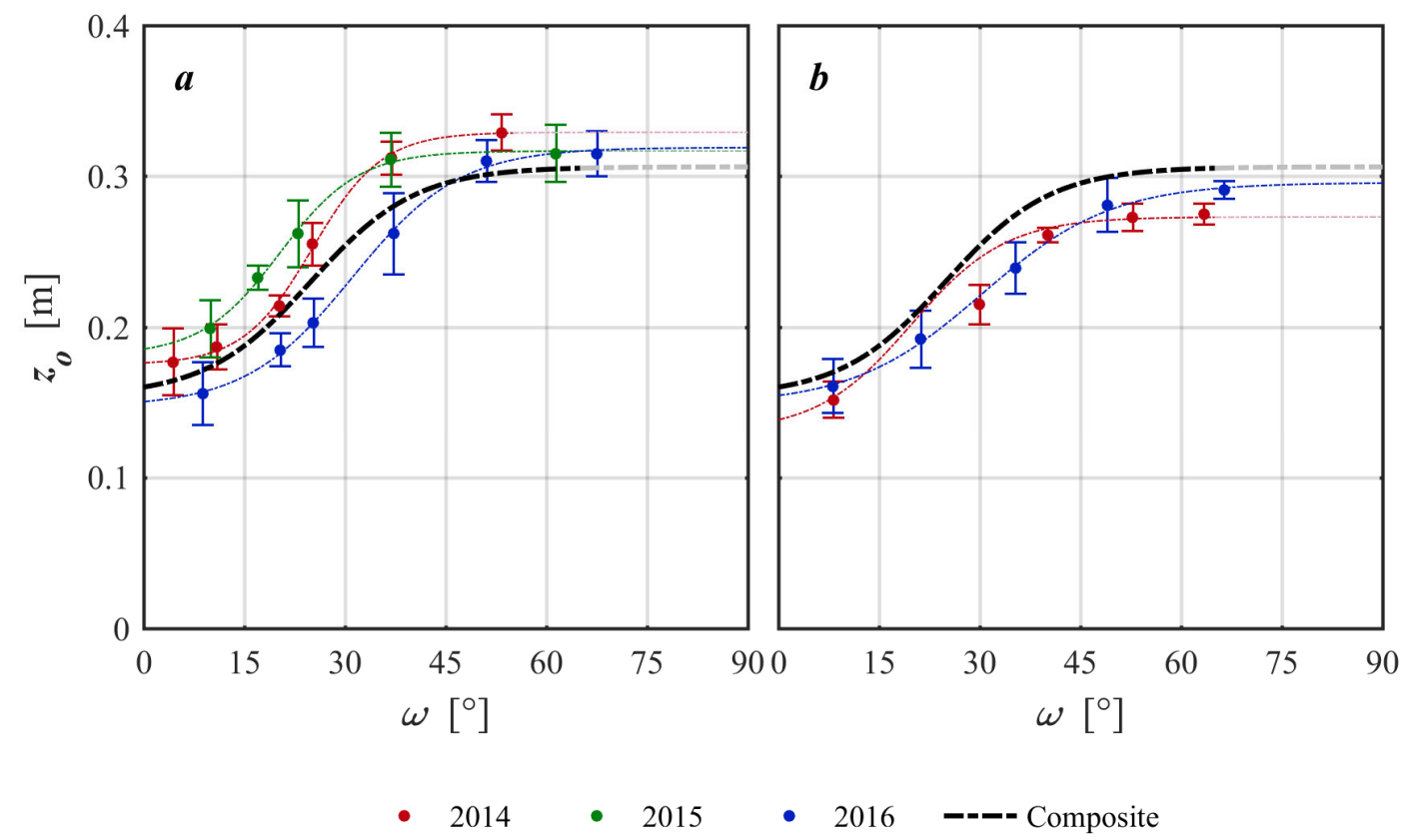

Figure 5 The best-fit sigmoidal relationships between roughness length (zo) and relative wind direction $(\omega)$ is shown for $\boldsymbol{a}$ ) Vineyard 1 and $\boldsymbol{b}$ ) Vineyard 2. The error bars indicate \pm 1 standard deviation. The composite curve was determined by fitting all data from Vineyard 1 and 2. 
Nonetheless, the relationships are unique both vineyard-to-vineyard and year-to-year.

406 These variations are likely due to modest differences vine management practices that influence

407 the amount and distribution of vine biomass, thus effective roughness of the surface. For

408 example, pruning was more aggressive at Vineyard 1 in 2015 compared to other years. As a

409 result, there were fewer vine shoots intruding into the inter-row space where they can interact

410 with the wind flow. In turn, this decreases the effective roughness of the surface, particularly

411 when $\omega$ is parallel to the rows. Similarly, the lower biomass in Vineyard 2 - as discussed above,

412 the LAI of Vineyard 2 is approximately $0.25 \mathrm{~m}^{2} \mathrm{~m}^{-2}$ lower than the LAI at Vineyard $1-$ implies

413 there is less vegetation, i.e. roughness elements, for the vegetation to interact with and, therefore,

414 a lower $z_{o}$.

415 For the modeling purposes, a single composite relationship between $z_{o}$ and $\omega$ was developed.

416 The resulting function has the same sigmoidal form as the curves for the individual year with

417 values of $0.1642,0.3107,0.1270$, and 24.52 for $\xi_{\min }, \xi_{\max }, \beta$, and $\omega_{o}$ respectively (Fig. 5). While

Table 3 The error in the estimates of the roughness length when using the best-fit relationship with relative wind direction is summarized in terms of both the mean absolute difference (MAD) and root mean square difference (RMSD). The root mean square error is also partitioned between the random and systemic components.

\begin{tabular}{|c|c|c|c|c|c|}
\hline \multirow[b]{2}{*}{ Year } & \multicolumn{3}{|c|}{ Vineyard 1} & \multicolumn{2}{|c|}{ Vineyard 2} \\
\hline & 2014 & 2015 & 2016 & 2014 & 2016 \\
\hline \multicolumn{6}{|c|}{ Individual Years } \\
\hline MAD & 0.002 & 0.002 & 0.002 & 0.008 & 0.002 \\
\hline RMSD & 0.003 & 0.002 & 0.002 & 0.014 & 0.002 \\
\hline RMSD $_{\mathbf{R}}$ & 0.003 & 0.002 & 0.002 & 0.012 & 0.002 \\
\hline RMSDs $_{\text {s }}$ & 0.000 & 0.001 & 0.000 & 0.008 & 0.001 \\
\hline \multicolumn{6}{|c|}{ Composite } \\
\hline MAD & 0.012 & 0.021 & 0.022 & 0.035 & 0.027 \\
\hline RMSD & 0.015 & 0.023 & 0.025 & 0.036 & 0.028 \\
\hline $\mathbf{R M S D}_{\mathbf{R}}$ & 0.005 & 0.009 & 0.009 & 0.006 & 0.009 \\
\hline RMSDs $_{\mathrm{S}}$ & 0.015 & 0.021 & 0.024 & 0.035 & 0.027 \\
\hline
\end{tabular}


418 the error, which averaged $8.3 \%$, is greater than that seen for the individual years, it still suggests

419 reasonable agreement. Not unexpectedly, the preponderance of the error is due to systemic bias

420 when the composite relationship is used to determine $z_{o}$. For example, the composite relationship

421 systematically overestimates $z_{o}$ by approximately $0.039 \mathrm{~m}$ at Vineyard 2 during 2016. More

422 generally, the effect of the systemic bias can be most easily seen through the decomposition of

423 the RMSD (Table 3). For the best-fit relationships determined for individual years, between $72 \%$

424 and $100 \%$ of the error can be attributed to random error. If Vineyard 2 is neglected during 2014 ,

425 this range is between $95 \%$ and $100 \%$. In contrast when the composite relationship is used, only

426 between $3 \%$ and $12 \%$ of the total error can be attributed to random error while between $88 \%$ and

$42797 \%$ of the error is systemic in nature.

428 Overview of the Model Intercomparison

429 To investigate the impact of the roughness parameterization on the modeled fluxes of

430 heat and moisture, the output from three variants of the TSEB model were compared. The first

431 version of the model (TSEBSTD) uses the standard parameterization estimating the roughness

432 parameters as a fraction of $h_{c}$. The second version (TSEBOPN) also considers the canopy

433 geometry and vegetation density following the approach of Schaudt and Dickinson (2000). The

434 final version (TSEBVIN) uses the mean $d_{o}$ estimated from the observations and the relationship

435 between $z_{o}$ and $\omega$ derived from the observational data. All other components of the three versions

436 of the TSEB model are the same. The models were run over both vineyards for the years 2014 to

437 2016. The comparative analysis focused on daytime non-advective periods during May through

438 August each year. Herein, daytime is defined here as period when the incident solar radiation

439 exceeded $100 \mathrm{~W} \mathrm{~m}^{-2}$. Since the onset of local advection typically occurred in mid-afternoon, the

440 analysis considered the period nominally from 0700 to 1500 each day. This period includes

441 stable to unstable atmospheric conditions. 
Model Intercomparison of the Roughness Parameters

443 As can be seen in Figure 6, the different versions of the TSEB model yielded very

444 different estimates of $d_{o}$. For all years and both vineyards, the $d_{o}$ estimates from TSTEBSTD

445 typically ranged between $1.35 \mathrm{~m}$ and $1.55 \mathrm{~m}$ and averaged $1.46 \mathrm{~m}$. Overall, the typical range of

446 the $d_{o}$ estimates from TSEB ${ }_{O P N}$, which averaged $0.96 \mathrm{~m}$, was between $0.84 \mathrm{~m}$ and $1.07 \mathrm{~m}$. In

447 turn, the overall MAD between the $\mathrm{d}_{\mathrm{o}}$ estimates from TSEBVIN and those from TSEBSTD and

448 TSEBopn were $0.08 \mathrm{~m}$ and $0.44 \mathrm{~m}$, respectively. Equivalently, the estimates from TSEBvin were

$4496 \%$ lower than TSEBsTD, on average; at the same time, they were $46 \%$ greater than the $d_{o}$

450 estimates from TSEBOpN. If the individual vineyards are considered, the estimates of $d_{o}$ from the

451 TSEBStD and TSEBOPN are slightly lower at Vineyard 2 compared to Vineyard 1. In both cases,

452 the difference is approximately $0.05 \mathrm{~m}$ and is due to the lower LAI at Vineyard 2.

453 The roughness length calculated by TSEBvin was typically less than $z_{o}$ calculated by

454 either TSEBStD or TSEBopn (Fig. 7). The estimates of $z_{o}$ from TSEBstD, which typically ranged

455 between $0.26 \mathrm{~m}$ and $0.30 \mathrm{~m}$, varied by approximately $7 \%$ about their mean of $0.28 \mathrm{~m}$. while the

456 estimates calculated by TSEBopN, which typically ranged between $0.47 \mathrm{~m}$ and $0.49 \mathrm{~m}$ and

457 averaged $0.48 \mathrm{~m}$, varied by $2 \%$ about their mean. The estimates of $z_{o}$ determined by TSEBVIN

458 ranged between $0.17 \mathrm{~m}$ and $0.31 \mathrm{~m}$ and averaged $0.23 \mathrm{~m}$. As a result, the difference in the

459 estimates of $z_{o}$ from TSEBstD and TSEBvin in terms of MAD was $0.06 \mathrm{~m}$ or, equivalently $21 \%$.

460 More strikingly, the difference in the estimates from TSEBopn and TSEBVIN was $0.25 \mathrm{~m}$ or

461 nearly 53\%. Again, there is no evident seasonal trend in the discrepancy in the estimates. This is

462 not unexpected since the variability in the $z_{o}$ calculated by TSEBVIN is linked to wind direction

463 which changes on much shorter time scales. The variability in the wind direction for the hourly

464 measurements, was typically between $5^{\circ}$ and $30^{\circ}$. 

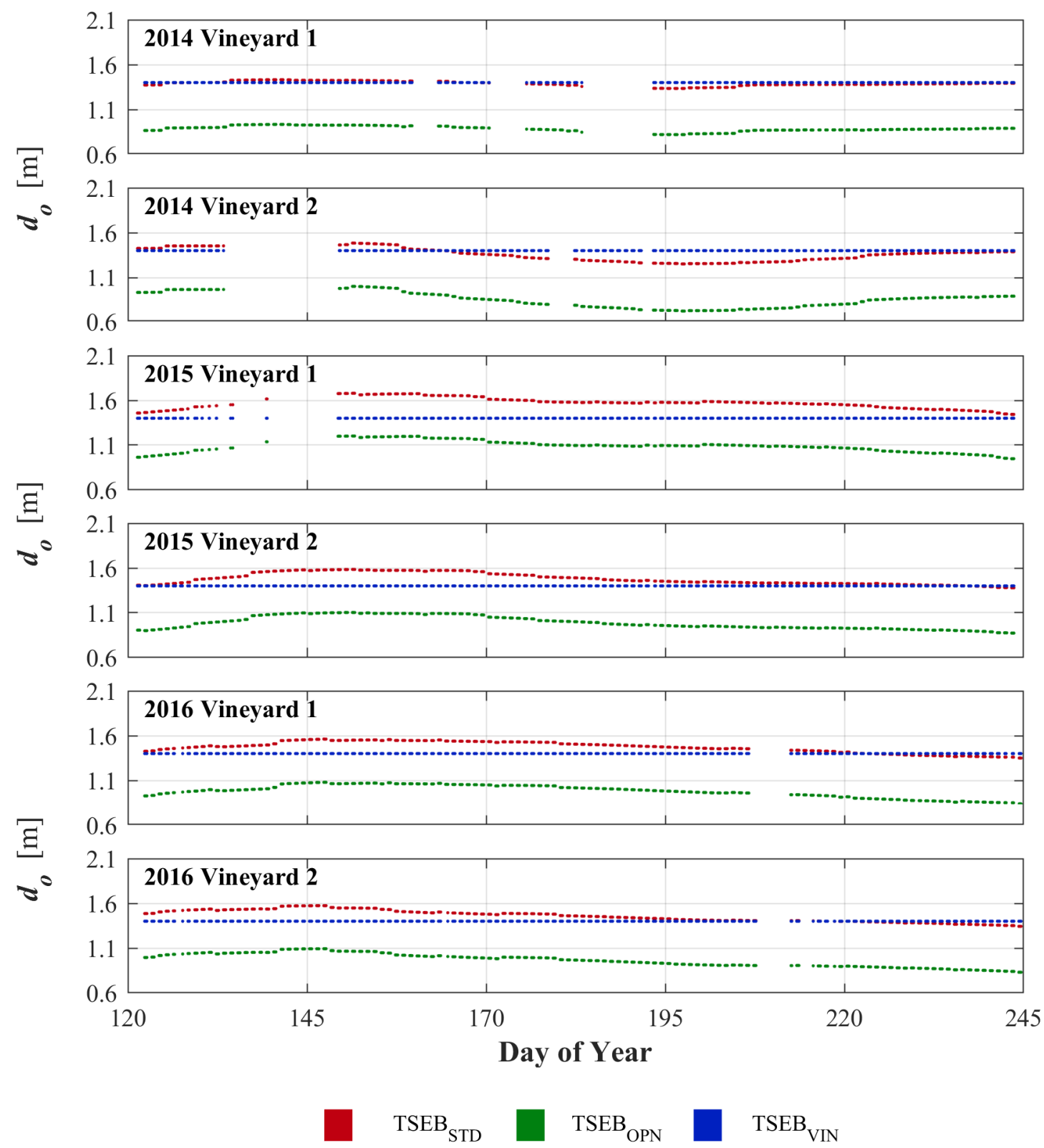

Figure 6 The estimates of displacement height from each version of the TSEB model are shown. 

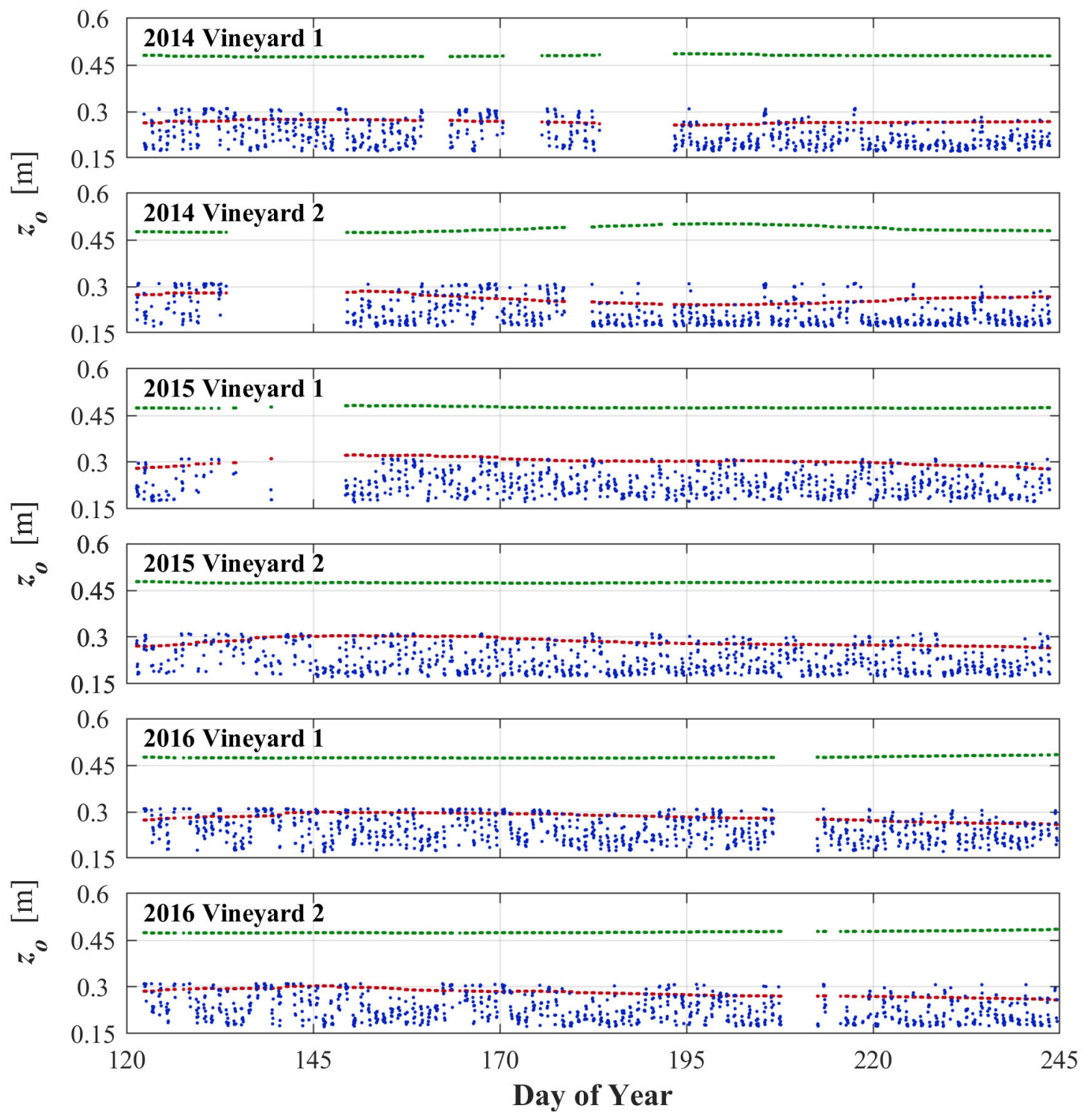

$\square$ TSEB $_{\text {STD }} \square$ TSEB $_{\text {OPN }} \square$ TSEB $_{\text {VIN }}$

Figure 7 The estimates of roughness length from each version of the TSEB model are shown. 
Model Intercomparison of the Turbulent Fluxes

The intercomparison of the model output showed consistent, albeit modest, differences in

467 the turbulent fluxes, $H$ and $\lambda E$. Moreover, since the available energy calculated by all versions of

468 the TSEB model is the same, the difference in one flux is counterbalance by a commensurate but

469 opposite difference in the other. In other words, any increase (decrease) in $H(\lambda E)$ is balanced by

470 a decrease (increase) in $\lambda E(H)$ of equal magnitude. Also, the fluxes from the canopy are

471 unchanged by changes in the roughness parameters. This is due to the linkage between $r_{x}$ and $T_{c}$

472 in the TSEB model physics; because the quantity $r_{*}$ is used in the calculation $T_{c}$, any change in $r_{x}$

473 results in compensatory change in $T_{c}$ such that, all else being equal, the models yields the same

474 turbulent fluxes. Therefore, the changes in the turbulent fluxes due to changes in the roughness

475 parameters are the result in changes in the fluxes from the soil only.

Given that any change in $H$ results in an equivalent change in $\lambda E$ and canopy flux is

477 unchanged by changes in the roughness parameters, the focus of this analysis is on the soil and

478 total $H$. Superficially, with seasonal values of MAD and RMSD ranging from slightly more than

$4791.4 \mathrm{~W} \mathrm{~m}^{-2}$ to $3.1 \mathrm{~W} \mathrm{~m}^{-2}$ and $1.7 \mathrm{~W} \mathrm{~m}^{-2}$ to $4.0 \mathrm{~W} \mathrm{~m}^{-2}$, respectively, the difference in $H$ calculated

480 by TSEBSTD and TSEBvin appears trivial. This is equivalent to an average decrease in $H_{s}$ and $H_{t o t}$

481 calculated by TSEBVIN of $1.5 \%$ and nearly $3 \%$, respectively. For the sake of comparison, the

482 increases in both $\lambda E_{s}$ and $\lambda E_{\text {tot }}$ were less than $1 \%$. Additionally, by partitioning the RMSD, it was

483 found that approximately $87 \%$ of the difference can be attributed to systemic differences in the

484 modelled fluxes.

On an hourly timescale, however, the difference between TSEBSTD and TSEBVIN can be

486 as much as $12 \mathrm{~W} \mathrm{~m}^{-2}$ or $7 \%$ and $13 \%$ and $7 \%$ for $H_{s}$ and $H_{t o t}$, respectively. As can be seen in

487 Figure 8, the largest differences occur near mid-day when the available energy is greatest. It can 
488 also be seen that the differenced were more mixed; although the fraction varies somewhat with

489 time of day, on average, the flux from TSEBvin exceeded TSEBstD for approximately $18 \%$ of

490 the observational periods. This is particularly evident for Vineyard 2 where the magnitude of

491 differences tended to be larger and more varied. For a given time of day, the range of differences

492 in the fluxes from TSEBstD and TSEBVIN was typically near $14 \mathrm{~W} \mathrm{~m}^{-2}$ at Vineyard 2 but only

$4939 \mathrm{~W} \mathrm{~m}^{-2}$ at Vineyard 1. Finally, it can be seen that the peak difference occurred about an hour

494 later in the day at Vineyard 2 compared to Vineyard 1. While the cause of the differences

495 between the two vineyards is unclear, it is hypothesized that they due to differences in vegetation

496 density and canopy geometry. They may also reflect the effect of using a composite function to

497 estimate $z_{o}$ which compared to the individual observed relationships tended to underestimate $z_{o}$

498 for Vineyard 1 while overestimating it for Vineyard 2.
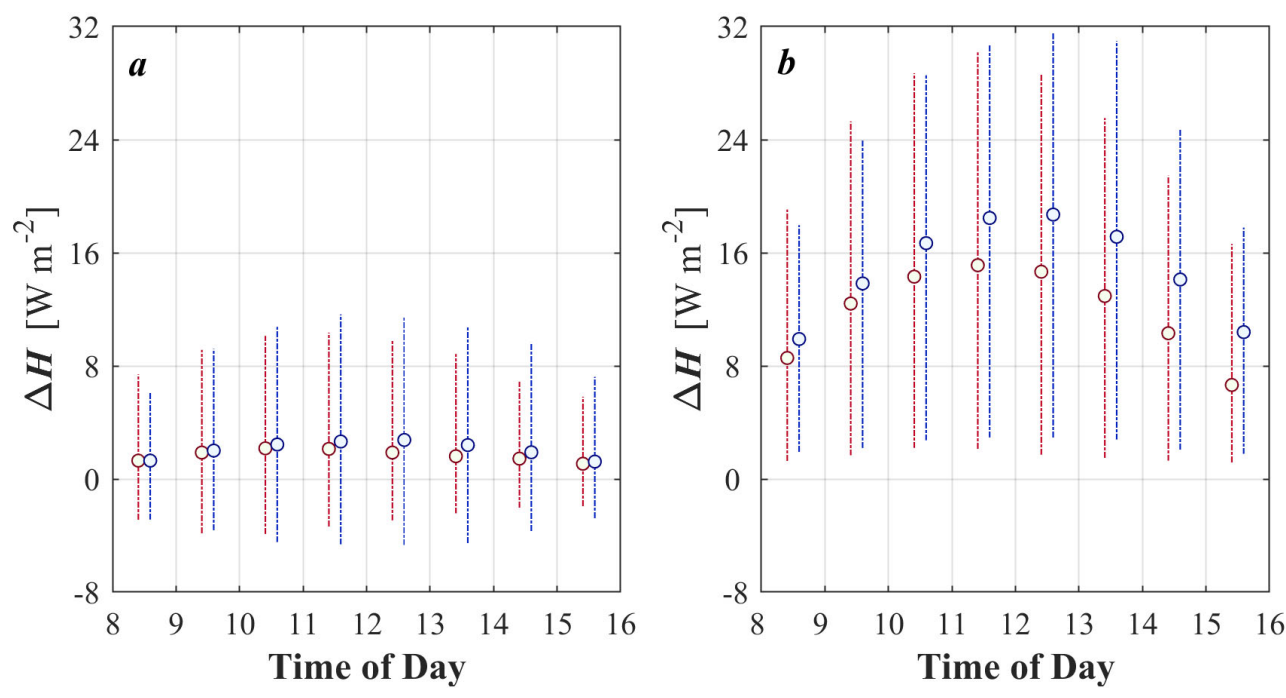

o Vineyard 1 V Vineyard 2

Figure 8 The mean difference of the modeled sensible heat flux calculated by $a$ ) TSEB ${ }_{\text {STD }}$ and TSEB VIN and $\boldsymbol{b})$ TSEB $_{\mathrm{OPN}}$ and TSEB $\mathrm{VIN}$ is shown for each vineyard as a function of the time of day. The bars indicate the range of differences observed during each hourly period. Note, the data from each vineyard is staggered slightly in time to improve clarity. 
Similarly, $H_{s}$ and $H_{\text {tot }}$ calculated by TSEBvin was modestly lower than the flux calculated

500 by TSEBopn. On average, the seasonal MAD was $13 \mathrm{~W} \mathrm{~m}^{-2}$ and RMSD was $14 \mathrm{~W} \mathrm{~m}^{-2}$. This is

501 equivalent to decrease in $H_{s}$ and $H_{t o t}$ of approximately $17 \%$ and $10 \%$, respectively. However,

502 when considered on an hourly basis, the difference in the modeled fluxes could be as large as

$50332.0 \mathrm{~W} \mathrm{~m}^{-2}$ or, equivalently, $18 \%$ of $H_{\text {tot }}$ and $10 \%$ of $\lambda E_{\text {tot. }}$. While the estimates of $H_{s}$, thus $H_{\text {tot }}$,

504 from TSEBOPN is always greater than TSEBVIN during the daytime period, the same vineyard-to-

505 vineyard differences are apparent for the fluxes output by TSEBvin and TSEBopN. In this case,

506 the range of differences in the modeled fluxes averaged $21 \mathrm{~W} \mathrm{~m}^{-2}$ at Vineyard 1 and $24 \mathrm{~W} \mathrm{~m}^{-2}$ at

507 Vineyard 2. Additionally, the hourly MAD and RMSD at Vineyard 2 averaged $15 \mathrm{~W} \mathrm{~m}^{-2}$ and

$50817.0 \mathrm{~W} \mathrm{~m}^{-2}$, respectively, compared to $12 \mathrm{~W} \mathrm{~m}^{-2}$ and $13 \mathrm{~W} \mathrm{~m}^{-2}$, respectively, at Vineyard 1.

509 Again, this indicates that the difference in the flux estimates are more varied at Vineyard 2.

510 Finally, it can be seen in Figure 8 that the again peak difference occurred about an hour later in

511 the day at Vineyard 2 compared to Vineyard 1.

512 Given the change in the roughness parameters, especially between TSEBopN and

513 TSEBVIN, the relatively small change in the turbulent fluxes might appear counterintuitive. While

$514 d_{o}$ calculated by TSEBopn was, on average, $46 \%$ less than $d_{o}$ calculated by TSEBvin and $z_{o}$

515 calculated by TSEBopn was, on average, 53\% greater than that calculated by TSEBvin, $H_{t o t}$

516 changed by only $10 \%$. The limited sensitivity of the TSEB model to the roughness parameters

517 can be understood by recognizing that these quantities are primarily used to calculate the canopy

518 level and sub-canopy wind speed terms used the TSEB model to determine $r_{s}$ and ultimately $H_{s}$

519 and $H_{\text {tot }}$ (See Eq. 6 through 8 above). In the case of TSEBopn and TSEBvin, the roughness

520 parameters move in opposite directions; in other words, $d_{o}$ is greater while $z_{o}$ is lower for

521 TSEBVIn compared to TSEBopn. As a result, the changes in the roughness parameters partially 
522 compensate for one another when calculating the logarithmic quantities in the relationship for $U_{c}$

523 (Eq. 8). The sensitivity of the calculation of $U_{c}$ to changes in the roughness parameters is further

524 reduced because the logarithmic quantities change more slowly than their arguments. Moreover,

525 while the wind speed just above the soil surface $\left(U_{s}\right)$ changes proportionally with $U_{c}$, the rate of

526 change is lower because the exponential term in Eq. 7 must be between 0 and 1; for this study

527 that quantity ranged between approximately 0.70 and 0.75 .

\section{CONCLUSIONS AND FUTURE WORK}

529 The results of this study demonstrate that $z_{o}$ varies as a function of $\omega$ in open and highly

530 structured canopies such as vineyard. Specifically, a clear sigmoidal relationship was found

531 linking $z_{o}$ to $\omega$ for the two vineyards considered in this study. It also showed that the relationship

532 was unique for a given vineyard and year. This suggests that other factors, such as the vegetation

533 density and vine management practices, also influence $z_{o}$. However, further study is needed to

534 identify the specific factors and quantify their role in controlling $z_{o}$. It is also needed to further

535 refine the relationships found in this study.

536 The work also showed that incorporating the methods for estimating the roughness

537 parameter developed in this study into the TSEB model results significant changes in the

538 modeled $d_{o}$ and $z_{o}$. The displacement height used by TSEBvin was $1.40 \mathrm{~m}$ or $0.06 \mathrm{~m}$ less than the

539 average do from TSEBSTD and $0.44 \mathrm{~m}$ greater than the average do from TSEBOpN. The effect on

$540 z_{o}$ was more pronounce. Averaging $0.23 \mathrm{~m}$, TSEBVIN typically produced the lowest estimates of

$541 z_{o}$, while TSEBopn produced the highest estimates; these averaged $0.48 \mathrm{~m}$. The average $z_{o}$ from

542 TSEBSTD was $0.28 \mathrm{~m}$. Although the differences in the roughness parameters could be large, the

543 did not impact the fluxes from the canopy and had only a modest effect on the fluxes from the

544 soil. Although the difference in flux estimates from TSEBSTD and TSEBvin could be nearly $12 \mathrm{~W}$ 
$545 \mathrm{~m}^{-2}$ at midday, MAD averaged approximately $2 \mathrm{~W} \mathrm{~m}^{-2}$ with TSEBvin partitioning slightly less

546 energy in $H_{s}$, thus $H_{t o t}$, compared to TSEBsTD. Similarly, the difference in the flux from

547 TSEBopn and TSEBVIN approached $32 \mathrm{~W} \mathrm{~m}^{-2}$ at midday but, on average, MAD was $13 \mathrm{~W} \mathrm{~m}^{-2}$.

548 Again, $H_{s}$ and $H_{\text {tot }}$ calculated by TSEBVIN was lower than that calculated by TSEBopN.

549 The results suggest that the TSEB model is largely insensitive to changes in the

550 roughness parameters. Because of this, along with the need for additional inputs that may not be

551 readily available and the site-specific nature of the relationship used to calculate $z_{o}$, the utility of

552 this approach may be limited for applications using the TSEB model. Given there is no clear

553 advantage to using the modified versions of the TSEB model, it is recommended that TSEBSTD is

554 used to model the fluxes over vineyards. Nonetheless, the approach may prove beneficial when

555 used with the TSEB model over other structured canopies such as orchards. It may also prove

556 valuable for improving other land surface models that are more sensitive to the roughness

557 parameters (e.g., Timmermans et al., 2007; Zhan et al., 1996); these potential uses of

558 relationships between environmental conditions and roughness deserve further evaluation. 


\section{ACKNOWLEDGMENTS}

The authors would like to thank the many researchers within the USDA and other

561 governmental agencies, university collaborators, and industry partners who have contributed to

562 the GRAPEX project. Specifically, the authors would like to thank E.\&J. Gallo Winery for

563 financial and logistical support and the staff of Viticulture, Chemistry, and Enology Division of

564 E.\&J. Gallo Winery for their assistance with data collection. The authors would also like to thank

565 Mr. Ernie Dosio of Pacific Agri Lands Management and the vineyard staff at the Borden/

566 McMannis Vineyard for their cooperation and support of this research. Finally, the authors

567 would like to acknowledge financial support for this research from NASA [NNH16ZDA001N-

568 WATER]. USDA is an equal opportunity provider and employer.

\section{CONFLICT OF INTEREST}

570 On behalf of all authors, there is no conflict of interest. 
572 Acevedo-Opazo C, Ortega-Farias S, Fuentes S (2010) Effects of grapevine (Vitis vinifera L.)

573 water status on water consumption, vegetative growth and grape quality: An irrigation

574 scheduling application to achieve regulated deficit. Agric Water Manage 97: 956-964.

Alfieri JG, Kustas WP, Prueger JH, Hipps LE, Chavez JL, French AN, Evett SR (2011) Intercomparison of nine meteorological stations during the BEAREX08 field campaign. J Atmos

577 Oceanic Tech 28: 1390-1406.

578

579

580

581

582

583

584

585

586

587

588

589

590

591

592

593

594

595

596

597

598

599

600

601

602

603

604

605

606

607

608

609

Anderson MC, Norman JM, Diak GR, Kustas WP, Mecikalski JR (1997).A two-source timeintegrated model for estimating surface fluxes using thermal infrared remote sensing. Remote Sens Environ 60: 195-216.

Anderson MC, Norman JM, Mecikalski JR, Torn RD, Kustas, WP, Basara, JB (2004) A multiscale remote sensing model for disaggregating regional flues to micrometeorological scales. $\mathrm{J}$ Hydrometeorol 5: 343-363.

Anderson MC, Norman JM, Kustas WP, Li F, Prueger JH, Mecikalski JR (2007) A climatological study of evapotranspiration and moisture stress across the continental United States: 1. Model formulation. J Geophys Res 112: doi:10.1029/2006JD007506.

Arno J, Martınez-Casanovas J, Ribes-Dasi M, Rosell JR (2009) Review. Precision viticulture. Research topics, challenges and opportunities in site-specific vineyard management. Spanish J Agric Res 7:779-790.

Anderson MC, Norman JM, Kustas WP, Li F, Prueger JH, Mecikalski JM (2005) Effects of vegetation clumping on two-source model estimates of surface energy fluxes from an agricultural landscape during SMACEX. J Hydrometeorol 6: 892-909.

Arya P (2001) Introduction to micrometeorology. Academic Press, San Diego.

Baluja J, Diago MP, Balda P, Zorer R, Meggio, F, Morales F, Tardaguila, J (2012) Assessment of vineyard water status variability by thermal and multispectral imagery using an unmanned aerial vehicle (UAV). Irrig Sci 30: 511-522.

Bellvert J, Marsal J, Girona J, Zarco-Tejada PJ (2015). Seasonal evolution of crop water stress index in grapevine varieties determined with high-resolution remote sensing thermal imagery. Irrig Sci 33: 81-93.

Brunet Y, Finnigan JJ, Raupach MR (1994) A wind tunnel study of air flow in waving wheat: single-point velocity statistics. Boundary-Layer Meteorol 70:95-132

Brutsaert, W (1982) Evaporation into the atmosphere. D Reidel Publishing Company, Dordrecht. California Department of Food and Agriculture (2017) California grape acreage report 2016. Available online at: http://www.nass.usda.gov/ca. Accessed 21 April 2018.

Campbell GS, Norman JM (1998), An introduction to environmental biophysics, SpringerVerlag, New York.

Campos I, Neale CMU, Calera A, Balbontin, C, Gonzalez-Piqueras J (2010) Assessing satellitebased basal crop coefficients for irrigated grapes (Vitis vinifera L.). Agric Water Manage 98: 45-54. 
610 Chahine A, Dupont S, Sinfort C, Brunet Y (2014) Wind flow dynamics over a vineyard. Bound611 Layer Meteorol 151: 557-577.

612 Chapman DM, Roby G, Ebeler SE, Guinard JX, Matthews MA (2005) Sensory attributes of

613 Cabernet Sauvignon wines made from vines with different water status. Aust J Grape Wine Res

614 11: 339-347.

615 Chaves MM, Santos TP, Souza CR, Ortuñ MF, Rodrigues ML, Lopes CM, Maroco JP, Pereira 616 JS (2007) Deficit irrigation in grapevine improves water-use efficiency while controlling vigour 617 and production quality. Ann Appl Biol 150:237-252.

618 Dyer AJ (1974) A review of flux profile relationships. Bound-Layer Meteorol, 7: 363-372.

619 Gao F, Anderson MC, Kustas WP, Wang Y (2012) A simple method for retrieving Leaf Area 620 Index from Landsat using MODIS LAI products as reference. J. Appl. Remote Sens., 6, DOI: $621 \quad 10.1117 / . J R S .1116 .063554$

622 Goring DG, Nikora VI (2002) Despiking acoustic doppler velocimeter data. J Hydrol Eng 128 : $623 \quad 117-126$.

624 Goudriaan, J (1977) Crop micrometeorology: A simulation study. Center for Agricultural 625 Publications and Documentation, Wageningen.

626 Hicks BB (1973) Eddy fluxes over a vineyard. Agric Meteorol 12: 203-215.

627 John Dunham and Associates (2016) The 2015 economic impact study of the California wine 628 industry. Available online at: http://www.wineinstitute.org/resources/statistics. Accessed 6 629 November 2017.

630 Jonsson P, Eklundh L (2004) TIMESAT - a program for analyzing time-series of satellite sensor 631 data. Comput. Geosci. 30: 833-845.

632 Kaimal JC, Finnigan JJ (1994) Atmospheric boundary layer flows. Oxford University Press, 633 Oxford.

634 Kustas WP, Norman JM (1997) A two-source approach for estimating turbulent fluxes using 635 multiple angle thermal infrared observations. Water Resour Res 33: 1495-1508.

636 Kustas WP, Norman JM (1999) Evaluation of soil and vegetation heat flux predictions using a 637 simple two-source model with radiometric temperatures for partial canopy cover. Agric For 638 Meteorol 94:13-29.

639 Kustas WP, Norman JM (2000) A two-source energy balance approach using directional 640 radiometric temperature observations for sparse canopy covered surfaces. Agron J 92: 847-854.

641 Kustas WP, Alfieri JG, Anderson MC, Colaizzi PD, Prueger JH, Evett SR, Neale CM, French 642 AN, Hipps LE, Chávez JL, Copeland KS, Howell TA (2012) Evaluating the two-source energy 643 balance model using local thermal and surface flux observations in a strongly advective irrigated 644 agricultural area. Adv Water Resour 50: 120-133.

645 Legates DR, McCabe GR (1999) Evaluating the use of "goodness-of-fit" measures in hydrologic 646 and hydroclimatic model validation. Water Resour Res 35: 233-241.

647 Lindroth A (1993) Aerodynamic and canopy resistance of short-rotation forest in relationship to 648 leaf area index and climate. Bound-Layer Meteorol 66: 265-279. 
Liu H, Peters G, Foken T (2001) New equations for sonic temperature variance and buoyancy heat flux with an omnidirectional sonic anemometer. Bound-Layer Meteorol 100: 459-468.

651 Lobell DB, Cahill KN, Field CB (2007) Historical effects of temperature and precipitation on 652 California crop yields. Climatic Change 81: 187-203.

653 Massman WJ (2001) A simple method for estimating frequency response corrections for eddy 654 covariance systems. Agric For Meteorol 104: 185-198.

655 Massman WJ, Lee X (2002) Eddy covariance flux corrections and uncertainties in long term 656 studies of carbon and energy exchanges. Agric For Meteorol 113: 121-144.

657 Maurer KD, Hardiman BS, Vogel CS, Bohrer G (2013) Canopy-structure effects on surface 658 roughness parameters: Observations in a Great Lakes mixed-deciduous forest. Agric For 659 Meteorol 177: 24-34.

660 Maurer KD, Bohrer G, Kenny WT, Ivanov VY (2015) Large-eddy simulations of surface 661 roughness parameter sensitivity to canopy-structure characteristics. Biogeosci 12: 2533-2548.

662 MFK Research (2007) The impact of wine, grapes, and grape products on the American 663 economy. Available online at: https://www.wineinstitute.org/files/mfk_us_econ_report07.pdf. 664 Accessed 6 November 2017

665 Nieto H, Kustas WP, Torres-Rúa A, Alfieri JG, Gao F, Anderson MC, White WA, Song L, del 666 Mar Alsina M, Prueger JH, McKee M, Elarab M, McKee LG (2018a) Evaluation of TSEB turbulent fluxes using different methods for the retrieval of soil and canopy component temperatures from UAV thermal and multispectral imagery. Irrig Sci, this issue. Nieto H, Kustas W, Gao F, Alfieri J, Torres A, Hipps L (2018b) Impact of different withincanopy wind attenuation formulations on modelling evapotranspiration using TSEB. Irrig Sci, this issue.

Norman JM, Kustas WP, Humes KS (1995) A two-source approach for estimating soil and 673 vegetation energy fluxes from observations of directional radiometric surface temperature. Agric 674 Forest Meteorol 77: 263-293.

675 Ojeda H, Andary C, Kraeva E, Carbonneau A, Deloire A (2002) Influence of pre and postveraison water deficit on synthesis and concentration of skin phenolic compounds during berry growth of Vitis vinifera cv. Shiraz. Am J Enol Vitic 53: 261-267. experiment. Water Air Soil Pollut 75: 307-323.

Pagay V (2016) Effects of irrigation regime on canopy water use and dry matter production of 'Tempranillo' grapevines in the semi-arid climate of Southern Oregon, USA. Agric Water 684 Paulson CA (1970) The mathematical representation of wind speed and temperature profiles in 
Pitman AJ (1994) Assessing the sensitivity of a land-surface scheme to the parameter values using a single column model. J Clim 7: 1856-1869.

691 Priestley CHB, Taylor RJ (1972) On the assessment of surface heat flux and evaporation using 692 large-scale parameters. Mon Weather Rev 100: 81-92.

693 Raupach M (1992) Drag and drag partition on rough surfaces. Bound-Layer Meteorol 60: 375694395.

695 Raupach M (1994) Simplified expressions for vegetation roughness length and zero-plane 696 displacement as functions of canopy height and area index. Bound-Layer Meteorol 71: 211-216.

697 Riou C, Pieri P, Valancogne C (1987) Variation de la vitesse du vent a l'interieur et au-dessus 698 d'une vigne. Agric For Meteorol 39: 143-154.

699 Santanello JA, Friedl MA (2003) Diurnal variation in soil heat flux and net radiation. J Appl 700 Meteorol 42: 851-862.

701 Sauer TJ, Norman JM, Tanner CB, Wilson, TB (1995) Measurement of hea and vapor transfer at 702 the soil surface beneath a maize canopy using source plates. Agric For Meteorol 75: 161-189.

703 Schaudt KJ, Dickinson RE (2000) An approach to deriving roughness length and zero-plane 704 displacement height from satellite data, prototyped with BOREAS data. Agric For Meteorol 104: 705 143-155.

706 Semmens KA, Anderson MC, Kustas WP, Gao F, Alfieri JG, McKee L, Prueger JH, Hain CR, 707 Cammalleri C, Yang Y, Xia T, Sanchez L, Alsina MM, Velez M (2016) Monitoring daily 708 evapotranspiration over two California vineyards using Landsat 8 in a multi-sensor data fusion 709 approach. Remote Sens Environ 185: 155-170.

710 Sene KJ (1994) Parameterisations for energy transfers from a sparse vine crop. Agric For 711 Meteorol 71: 1-18.

712 Shaw RH, Pereira A (1982) Aerodynamic roughness of a plant canopy: A numerical experiment. 713 Agric Meteorol 26: 51-65.

714 Stull R (1988) Introduction to boundary layer meteorology. Kluwer Academic Publishers, 715 Dordrecht

716 Sun L, Gao F, Anderson MC, Kustas WP, Alsina M, Sanchez L, Sams B, McKee LG, Dulaney 717 WP, White A, Alfieri JG, Prueger JH, Melton H, Post K. (2017) Daily mapping of 30 m LAI, 718 NDVI for grape yield prediction in California vineyard. Remote Sensing, 9, 317.

719 Tanner CB, Thurtell, G (1969) Anemoclinometer measurements of Reynolds stress and heat transport in the atmospheric surface layer. Research and Development Technical Report to US Army Electronic Command, ECOM 66-G22-F. Department of Soil Sciences, University of Wisconsin.

Timmermans WJ, Kustas WP, Anderson MC, French AN (2007) An intercomparison of the Surface Energy Balance Algorithm for Land (SEBAL) and the Two-Source Energy Balance (TSEB) modeling schemes. Remote Sensing of Environment. 108, 369-384.

US Department of the Treasury, Alcohol and Tobacco Tax and Trade Bureau (2017) Statistical Report - Wine. Available online at: https://www.ttb.gov/wine/wine-stats.shtml. 
Verhoef A, McNaughton KG, Jacobs, AFG (1997) A parameterization of momentum roughness

729 length and displacement height for a wide range of canopy densities. Hydrol Earth Sys Sci 1: 8173091.

731 Webb EK, Pearman GL, Leuning R (1980) Correction measurements for density effects due to 732 heat and water vapour transfer. Q J Roy Meteorol Soc 106: 85-100.

733 Webb LB, Whetton PH, Barlow, EWR (2007) Modelled impact of future climate change on the 734 phenology of winegrapes in Australia. Australian J Grape Wine Res 13: 165-175.

735 Weiss A, Allen LH (1976) Vertical and horizontal air flow above rows of a vineyard. Agric 736 Meteorol 17: 433-452.

737 Willmott, CJ (1982) Some comments on the evaluation of model performance. Bull Amer 738 Meteorol Soc, 63: 1309-1313.

739 Willmott C, Matsuura K (2005) Advantages of the mean absolute error (MAE) over the root 740 mean square error (RMSE) in assessing average model performance. Climate Res 30: 79-82.

741 Willmott C, Robeson SM, Matsuura K (2012) A refined index of model performance. Int 742 J Climatol 321; 2088-2094.

743 Xia T, Kustas WP, Anderson MC, Alfieri JG, Gao F, McKee L, Prueger JH, Geli HME, Neale 744 CMU, Sanchez L, Alsina MM, Wang Z (2016) Mapping evapotranspiration with high-resolution 745 aircraft imagery over vineyards using one- and two-source modeling schemes. Hydrol Earth Syst 746 Sci 20:1523-1545.

747 Zarrouka O, Francisco R, Pinto-Marijuan M, Brossa R, Santos RR, Pinheiro C, Costa JM, Lopes 748 C, Chaves MM (2012) Impact of irrigation regime on berry development and flavonoids 749 composition in Aragonez (Syn. Tempranillo) grapevine. Agric Water Manage 114: 18-29.

750 Zeng X, Wang A (2007) Consistent Parameterization of Roughness Length and Displacement 751 Height for Sparse and Dense Canopies in Land Models. J Hydrometeorol 8: 730-737. 